\title{
Heart rate variability and arrhythmias evaluated with Holter in dogs with degenerative mitral valve disease
}

\author{
[Variabilidade da frequência cardíaca e arritmias detectadas pelo exame Holter em cães \\ com degeneração valvar mitral] \\ M.S. Oliveira ${ }^{1}$, R.A.L. $\mathrm{Muzzi}^{2}$, R.B. Araújo $^{1 *}$, L.A.L. $M u z z i^{2}$, D.F. Ferreira ${ }^{2}$, E.F. $S i l v a^{1}$ \\ ${ }^{1}$ Escola de Veterinária - Universidade Federal de Minas Gerais - Belo Horizonte, MG \\ ${ }^{2}$ Universidade Federal de Lavras - Lavras, MG
}

\begin{abstract}
Cardiac diseases promote alterations in the autonomic control of the heart, leading to an increase in heart rate and, as a result, a decrease in heart rate variability (HRV). The aim of this study was to evaluate if the development of heart failure secondary to degenerative mitral valve disease (DMVD) concurs with changes in autonomic modulation of heart rhythm which are assessed by long electrocardiography examination (Holter). Dogs were evaluated by clinical examination and echocardiography in order to be categorized into the following groups: Control (healthy; $n=6$ ), DMVD (disease without heart failure; $\mathrm{n}=8$ ), and DMVD heart failure (disease with heart failure; $\mathrm{n}=13$ ). Arrhythmias and frequency domain HRV were determined by Holter. Diseased animals, when compared to healthy, had significantly lower total power, which indicates overall HRV. DMVD heart failure dogs also showed other disturbances such as high incidence of supraventricular arrhythmias, high heart rate, little amount of pauses (2.0s long between consecutive heartbeats), longer time in tachycardia, shorter time in bradycardia, low high frequency (parasympathetic control), and high low frequency (sympathetic and parasympathetic control) when compared to control ( $\mathrm{p}<0.05)$. In DMVD dogs, Holter-derived variables changed with the development of heart failure.
\end{abstract}

Keywords: electrocardiography, heart failure, frequency-domain, cardiology

\section{RESUMO}

As cardiopatias cursam com alterações do controle autonômico do coração, resultando em taquicardia e consequente diminuição na variabilidade da frequência cardíaca (VFC). O objetivo deste estudo foi avaliar se o desenvolvimento de insuficiência cardíaca secundária à degeneração valvar mitral (DVM) leva a alterações no controle autonômico do coração, as quais podem ser determinadas pela eletrocardiografia contínua (Holter). Cães foram distribuídos em grupos experimentais após avaliação clínica e ecocardiográfica da seguinte maneira: controle (saudáveis; $n=6$ ), DVM sem insuficiência cardíaca $(n=8)$ e DVM com insuficiência cardíaca $(n=13)$. Arritmias e VFC foram determinadas pelo Holter. Animais portadores de DVM, quando comparados ao controle, apresentaram diminuição significativa da potência total, a qual é representativa de toda a VFC. Somente cães doentes e com insuficiência cardíaca apresentaram incidência elevada de arritmias supraventriculares, frequência cardíaca aumentada, pequena quantidade de pausas superiores a 2,0s entre batimentos consecutivos, permanência por mais tempo em taquicardia do que em bradicardia, diminuído índice de alta frequência (indicativo de controle parassimpático) e elevado índice de baixa frequência (indicativo de controle simpático e parassimpático), quando comparados ao controle $(p<0,05)$. Assim, conclui-se que, em cães portadores de DVM, as variáveis obtidas com o Holter apresentam-se alteradas devido ao desenvolvimento de insuficiência cardíaca.

Palavras-chave: eletrocardiografia, insuficiência cardíaca, domínio da frequência, cardiologia

Recebido em 23 de agosto de 2012

Aceito em 7 de novembro de 2013

*Autor para correspondência (corresponding author)

E-mail: baracat@vet.ufmg.br 


\section{INTRODUCTION}

Heart rate variability (HRV) refers to rhythmic variations in intervals between adjacent heart beats in an electrocardiogram (ECG) recording. Such variations reflect the sinoatrial node response to autonomic tone, thus, autonomic modulation of heart rhythm (Akselrod et al., 1981).There are some physiological causes involved in the regulation of the heart via the autonomic nervous system, such as respiration, thermoregulation, afferent inputs from sensory receptors and baroreceptors within the heart and great vessels, vasomotor regulation, and alterations in endocrine function (Stein et al., 1994).

The progression of heart disease leads to decreased HRV (i.e. increasing in sympathetic and decreasing in parasympathetic control of the heart), which is reported in people with congestive heart failure secondary to various cardiac diseases and often is explained as a sympathovagal imbalance. Although assessing autonomic modulation is difficult, HRV measurements are clinically useful in evaluating cardiovascular responsiveness to alterations in autonomic nervous system controls (Vanderlei et al., 2009).

Long-term ambulatory ECG recording, i.e. Holter, is a non-invasive and sensitive method for evaluating HRV (Stein et al., 1994). One method to study HRV is using frequency-domain (power spectrum) analysis which estimates how variance in heart rate (HR) is distributed as a function of frequency. Such analysis consists in converting the heart rate signal into its frequency components quantified as power. The total power (TP), i.e., the energy in the power spectrum up to $0.4 \mathrm{~Hz}$, is divided into four components: $\mathrm{HF}$ (high frequency) which comprises from 0.15 to $0.40 \mathrm{~Hz}$, or 9.0 to 24.0 cycles/min; LF (low frequency) which comprises from 0.04 to 0.15 $\mathrm{Hz}$, or 2.4 to 9.0 cycles/min; VLF (very low frequency) which comprises from 0.003 to 0.04 $\mathrm{Hz}$, or 0.2 to 2.4 cycles/min; ULF (ultra low frequency) which includes values below 0.003 $\mathrm{Hz}$ or below 0.2 cycle/min. These spectral components are usually measured in $\mathrm{ms}^{2}$. HF and LF variables may also be measured in normalizing units (n.u.) leading to a more precise analysis since the fluctuations related to VLF are minimized with such normalization. The parameters are then calculated as follows: $\mathrm{HF}$ (n.u.) $=\mathrm{HF} /(\mathrm{TP}-\mathrm{VLF}) \times 100 ; \mathrm{LF}$ (n.u.) $=\mathrm{LF} /(\mathrm{TP}-$ VLF)X100 (Stein et al., 1994; Calvert, 1998; Olsen et al., 1999). It is known that the HF component indicates alterations related to respiratory cycle being controlled by parasympathetic tonus. LF and VLF components indicate alterations related to baroreceptors and rennin angiotensin system, respectively. Both components are controlled by sympathetic and parasympathetic tonus. ULF, however, has unclear physiological mechanisms, but appears to be under sympathetic and parasympathetic control. Another way to infer about HRV is to calculate the $\mathrm{LF} / \mathrm{HF}$ ratio which indicates the imbalance between sympathetic and parasympathetic activities (Stein et al., 1994; Calvert, 1998). In the initial phase of heart failure, the autonomic control of heart is already modified, with increase of heart rate and reduction of its variability (Stein et al., 1994). Thus, the knowledge of HRV indexes is an important tool in the early diagnosis of heart failure. Häggström et al. (1996) demonstrated an HRV decrease in Cavalier King Charles Spaniel dogs with mitral regurgitation by evaluating an index obtained from ordinary ECG recordings. Since such publication few researches were conducted in dogs with mitral valve disease using Holter monitoring. Moreover, alterations on the autonomic control of the heart during the development of heart failure are poorly investigated. Considering that degenerative mitral valve disease (DMVD) is one of the most common heart diseases in small animals (Häggström et al., 2009) and that alterations in the autonomic control of the heart in such animals remain unclear, this research aimed to evaluate the effects of DMVD and heart failure on frequency-domain HRV and on arrhythmias using the Holter examination.

\section{MATERIALS AND METHODS}

This work was conducted with the approval of the Animal Care and Use Committee of Federal University of Minas Gerais State (CETEA Minas Gerais State - Brazil; protocol number: 225/2007).

Twenty-seven small breed dogs were randomly sampled from the Cardiology Service of the Veterinary Hospital. Owner consent was obtained prior to data collection. The 
classification of heart failure (from Stages A to D) was based on criteria used by the American College of Veterinary Internal Medicine (Atkins et al., 2009) and in order to be included on this research, animals were either healthy or with DMVD classified as Stages B, C or D. The animals were categorised into 3 groups: the control group, comprised of healthy dogs $(n=6$; no alterations in physical examination and echocardiography), DMVD group ( $\mathrm{n}=8$; DMVD dogs with heart murmur but without clinical signs of heart failure - Stage B), and DMVD heart failure group $(n=13$; diseased dogs with heart murmur and clinical signs of heart failure Stages C and D).

Echocardiogram images were performed considering two-dimensional (2-D), Doppler, and M-modes images, recorded following standard procedures (Boon, 2006). Animals with tricuspid, aortic, and pulmonic insufficiency were excluded from the study. The mean parameters evaluated were left atrial to aortic root ratio (LA/AO), measured using the 2-D right parasternal image (Hansson et al., 2002), and mitral E velocity, measured using pulsed Doppler (Boon, 2006).

For the electrocardiography (ECG) examination animals were placed in right lateral recumbence and electrodes were attached to forelimbs and hind limbs according to Tilley (1992). ECG tracings were recorded during five minutes.

Holter monitoring was performed using digital equipment and the data were analysed using computer software (Cardio Smart Professional CS 540, Cardio's, São Paulo, Brazil). Owners were instructed to make a daily record, on a specific sheet, informing all routine activities of the animal through the examination (patient diary). The analysis system was programmed with standard reference ranges for heart rates, PR and QT intervals, and QRS durations considering the canine species (Tilley, 1992). For HRV analyses, only normal-to-normal intervals were considered by identifying and excluding abnormal RR intervals from the recordings. The Holter analysis software provided the frequencydomain HRV variables (TP, VLF, LF, HF, and
$\mathrm{LF} / \mathrm{HF}$ ) which were computed and tabulated for the entire 24-hour recording period. The software program performed a spectral analysis of the heart rate signal by applying a Fast Fourier Transform (FFT) on successive and continuous 256 second sequences of the $1 \mathrm{~Hz}$ re-sampled heart rate signal. The TP was calculated from integration of power spectrum within the $\mathrm{HF}$ frequency band $(0.15$ to $0.4 \mathrm{~Hz})$, LF $(0.04$ to $0.15 \mathrm{~Hz})$ and VLF $(0.003$ to $0.04 \mathrm{~Hz})$. The $\mathrm{HF} / \mathrm{LF}$ power ratio was also calculated from the ratio of powers for each rhythm, given in normalized units. It should be remembered that the heart rate variance is equal to the total power of spectral analysis.

For statistical analysis all variables were assessed for normality of the residues using the ShapiroWilk test prior to evaluation. The assumption of homoscedasticity was verified by using the Bartlett's test (Box's M test). Then the data were analysed using an ordinary analysis of variance (ANOVA) followed by the Student-NewmanKeuls (SNK) test to verify differences in parametric variables (LA/AO ratio, mitral valve E peak velocity, LF n.u., HF n.u., mean heart rate) and in variables with normal distribution after logarithmic transformation (LF/HF ratio). A computational intensive analysis of variance was performed, considering 20,000 resamplings with replacement, using bootstrap SNK test for variables with non-normal distribution (Holter arrhythmias, pauses, time (min) remained in bradycardia and in tachycardia, TP $\mathrm{ms}^{2}$, HF $\mathrm{ms}^{2}$, LF $\mathrm{ms}^{2}$, and VLF $\mathrm{ms}^{2}$ ). Differences were considered significant when the probability of a Type I error was lower than $5 \%(\mathrm{p}<0.05)$. All analyses were performed using an available software program - SISVAR (Ferreira, 2000).

\section{RESULTS}

Twenty seven animals were evaluated, 13 males and 14 females. General information about the sample is shown in Tab. 1. Some of the diseased animals were already in medical therapy due to their clinical condition. All of them were clinically stable at the moment of the present research. 
Table 1. General information about the sample studied comprised of six healthy and 21degenerative mitral valve diseased dogs

\begin{tabular}{lccc} 
& \multicolumn{3}{c}{ Groups } \\
\cline { 2 - 4 } Characteristics & Control & DMVD & DMVD heart failure \\
\hline Age in years [mean (SD)] & $8.01(2.60)$ & $10.82(2.01)$ & $11.68(2.49)$ \\
Body weight in kg [mean (SD)] & $7.31(2.98)$ & $6.90(2.73)$ & $5.94(2.55)$ \\
sex & $\mathrm{M}(3) ; \mathrm{F}(3)$ & $\mathrm{M}(3) ; \mathrm{F}(5)$ & $\mathrm{M}(7) ; \mathrm{F}(6)$ \\
Clinical examination findings & - & Heart murmur (8) & Heart murmur (13) \\
& & & Cough (13) \\
Medical therapy & - & - & Pulmonary oedema (3) \\
& & & ACE inhibitor (13) \\
Dietary restriction & - & - & Diuretics $(11)$ \\
\hline
\end{tabular}

DMVD: degenerative mitral valve disease; SD: standard deviation; M: male; F: female; ACE: angiotensin-converting enzyme.

Echocardiograms revealed that the LA/AO ratio and mitral valve $\mathrm{E}$ peak velocity were significantly higher for the DMVD heart failure group than others (Tab. 2). Animals from the DMVD group had similar values to the control.

ECG recordings detected normal sinus rhythm (control $=2 ;$ DMVD $=1 ;$ DMVD heart failure $=$ 3), sinus arrhythmia (control = 3; DMVD = 2), sinus arrest $($ control $=1$; DMVD $=5$; DMVD heart failure $=4$ ), and sinus tachycardia (DMVD heart failure $=6$ ). One dog from the DMVD heart failure group had supraventricular extrasystoles.

Frequency-domain HRV indexes, which were evaluated in Holter recordings, are shown in Tab. 2. Diseased animals showed lower TP compared to healthy animals, indicating a decrease in HRV. Only DMVD heart failure dogs had frequency domain components significantly different from control. In general, variables indicative of parasympathetic control of the heart were decreased, while those related to sympathetic were increased.

Table 2. Echocardiography and Holter-derived variables [mean (SD)] of six healthy and 21 degenerative mitral valve diseased dogs

\begin{tabular}{lccc}
\multicolumn{1}{c}{ Variables } & \multicolumn{3}{c}{ Groups } \\
\cline { 2 - 4 } & Control & DMVD & DMVD heart failure \\
\hline LA/AO & $1.01(0.07) \mathrm{b}$ & $1.04(0.12) \mathrm{b}$ & $2.38(0.73) \mathrm{a}$ \\
Mitral E velocity $(\mathrm{m} / \mathrm{s})$ & $0.68(0.12) \mathrm{b}$ & $0.71(0.14) \mathrm{b}$ & $1.22(0.28) \mathrm{a}$ \\
TP $\left(\mathrm{ms}^{2}\right)$ & $21420.5(30479.8) \mathrm{a}$ & $7257.1(7849.5) \mathrm{b}$ & $2885.6(3756.3) \mathrm{b}$ \\
VLF $\left(\mathrm{ms}^{2}\right)$ & $544.5(363.9) \mathrm{a}$ & $873.8(755.8) \mathrm{a}$ & $296.5(278.6) \mathrm{a}$ \\
LF $\left(\mathrm{ms}^{2}\right)$ & $1026.2(788.7) \mathrm{a}$ & $1082.5(831.7) \mathrm{a}$ & $617.5(472.4) \mathrm{a}$ \\
HF $\left(\mathrm{ms}^{2}\right)$ & $19849.7(29563.5) \mathrm{a}$ & $5301(6605) \mathrm{b}$ & $1972(3669.1) \mathrm{b}$ \\
LF (n.u.) & $21.6(22.5) \mathrm{b}$ & $43.1(25.5) \mathrm{a}, \mathrm{b}$ & $59.8(21.7) \mathrm{a}$ \\
HF (n.u.) & $78.5(22.5) \mathrm{a}$ & $57.0(25.5) \mathrm{a}, \mathrm{b}$ & $40.3(21.7) \mathrm{b}$ \\
LF/HF & $0.39(0.49) \mathrm{b}$ & $0.85(1.03) \mathrm{a}$ & $1.07(1.23) \mathrm{a}$ \\
Mean heart rate $(\mathrm{bpm})$ & $96.3(11.5) \mathrm{b}$ & $96.6(16.6) \mathrm{b}$ & $124.7(18.9) \mathrm{a}$ \\
Time in bradycardia (min) & $491.2(221.8) \mathrm{a}$ & $597.6(360.5) \mathrm{a}$ & $109.2(248.9) \mathrm{b}$ \\
Time in tachycardia (min) & $118.7(108.1) \mathrm{a}$ & $121.8(127.9) \mathrm{a}$ & $392.7(332.0) \mathrm{b}$ \\
\hline
\end{tabular}

DMVD: degenerative mitral valve disease; LA/AO: left atrial to aortic root ratio; TP: total power; VLF: very low frequency; LF: low frequency; HF: high frequency; LF/HF: low frequency to high frequency ratio; ${ }^{\mathrm{a}, \mathrm{b}}$ statistical difference $(\mathrm{p}<0.05)$.

The predominant rhythms detected with Holter were sinus rhythm (15) and sinus arrhythmia (12). Almost all animals (26) showed pauses longer than 2.0 s between two consecutive normal heartbeats, indicating sinus arrest episodes, which were predominantly detected while 
animals were sleeping (according to notes written on the patient diary). Besides sinus arrest has been detected in almost all the samples, it was not the predominant rhythm for any dog. The median values for pauses were 5.5 (control), 70 (DMVD), and 1 (DMVD heart failure) and the longest pauses were $4.8 \mathrm{~s}$ (control), $3.9 \mathrm{~s}$ (DMVD), and 3.8s (DMVD heart failure). Control and DMVD dogs remained more at bradycardia, while DMVD heart failure dogs, in tachycardia. Such findings are also shown in Table 2.

Supraventricular extrasystoles were detected as follows. Control group: no episode (4 dogs); single and/or couplets (2); paroxysmal tachycardia (1). DMVD group: no episode (3), single and/or couplets (5), paroxysmal tachycardia (1). DMVD heart failure group: no episode (1); single and/or couplets (12), and tachycardia (9). The longest supraventricular tachycardia in the Control group was comprised of 69 ectopic beats, 30 ectopic beats in the DMVD group, and 105 ectopic beats in the DMVD heart failure group. Two dogs from the DMVD heart failure group also had persistent tachycardia, being the longest comprised by 3,064 ectopic beats, during 799.3s. No atrial fibrillation was diagnosed. Ventricular extrasystoles were not detected in the control group and only four animals from the DMVD group had single episodes. Nine dogs from the DMVD heart failure group had single and/or couplets episodes and in two of them bigeminism was observed, being the longest comprised by 63 cycles. Tab.3 summarizes atrial and ventricular ectopic beats findings.

Table 3. Supraventricular and ventricular arrhythmias diagnosed with Holter in six healthy and 21 degenerative mitral valve diseased dogs

\begin{tabular}{llcc}
\hline Extrasystole episodes & Control & Groups & \\
& & DMVD & DMVD heart failure \\
\hline Supraventricular origin & 4 & 3 & 1 \\
\hline 0 & 1 & 5 & 6 \\
$1-50$ & 1 & 0 & 0 \\
$51-150$ & 0 & 0 & 3 \\
$151-500$ & 0 & 0 & 3 \\
+500 & & & 4 \\
\hline Ventricular origin & 6 & 4 & 7 \\
\hline 0 & 0 & 3 & 1 \\
$1-50$ & 0 & 1 & 1 \\
$51-150$ & 0 & 0 & 0 \\
$151-500$ & 0 & 0 & \\
+500 & & & \\
\hline
\end{tabular}

DMVD: degenerative mitral valve disease

First degree AV-block was diagnosed in one dog from the DMVD heart failure group. Mobitz type II second degree AV-block (2:1 block) was detected in one dog from the Control group (a total of 2 episodes), in five of the DMVD group $(5 ; 34 ; 78 ; 189 ; 284)$, and in three of the DMVD heart failure group $(26 ; 107 ; 335)$. No third degree AV - Block was observed. One DMVD heart failure dog had a left bundle branch block. Ventricular escape beats were diagnosed in two dogs from the control group (4 and 14 episodes), in one from the DMVD (13) group, and in two from the DMVD heart failure (156 and $2,099)$ group. Considering all arrhythmias, the DMVD heart failure group showed higher supraventricular extrasystoles than the other groups $(\mathrm{p}<0.05)$.

\section{DISCUSSION}

The major findings of this study, alterations in frequency domain HRV and arrhythmias, highlight the importance of the Holter monitoring as a complementary examination which will bring additional information to the diagnosis and prognosis of dogs with DMVD. As expected, arrhythmias were more precisely detected using Holter than conventional ECG examination, due to the long evaluation time in Holter monitoring. Moreover, HRV, which is better evaluated with Holter, indicated alterations 
in the autonomic control of the heart in heart failure dogs with DMVD. It is important to remember that this work is not focus on comparing ECG and Holter, but on indicating which arrhythmias are most relevant in the development of heart failure in DMVD dogs. On the other hand, the evaluation of frequencydomain HRV was, indeed, a major purpose, since there is lack of information regarding HRV in heart failure dogs with DMVD.

Dogs with DMVD, mainly those in advanced stages of the disease, are expected to have left atrial enlargement and, therefore, supraventricular arrhythmias (Crosara et al., 2010). Indeed a high incidence of such arrhythmias was diagnosed in the dogs whose echocardiography examination revealed atrial enlargement. The only DMVD heart failure dog which didn't have any supraventricular arrhythmia was the one that had the lower atrial enlargement within the group. Although ventricular arrhythmias may be detected in dogs with DMVD (Crosara et al., 2010), they are more frequently diagnosed in other cardiac pathologies such as cardiomyopathy (Calvert et al., 2000; Martin et al., 2009; Wess et al., 2010). In fact, considering ECG recordings, no ventricular arrhythmias were detected in the sample studied and no ventricular tachycardia episodes were observed during Holter monitoring.

ECG data for heart rate indicated that almost all DMVD heart failure dogs had sinus tachycardia. This finding was corroborated by Holter data showing that DMVD heart failure dogs had the highest heart rate values. In addition, these dogs had little amount of pauses between consecutive heart beats, short duration of pauses, low HRV indexes which reflect vagal tonus, and high indexes which reflect sympathetic influence. Taken together such findings indicate parasympathetic withdrawn and sympathetic input under sinus node in DMVD dogs with heart failure. Since DMVD dogs without heart failure have a different pattern of autonomic modulation of the heart, it is possible to infer that heart failure development is the main reason for such differences. A similar pattern on modulation of heart control is reported for men with heart disease showing clinical signs of heart failure (Vanderlei et al., 2009).
Disturbances between sympathetic and vagal tonus under the heart must be diagnosed as early as possible since it is reported that such condition predisposes to myocardial electrical instability and sudden death in men (Kleiger et al., 1987; Carney et al., 2005).

Moreover, it is important to note that although DMVD dogs without heart failure have shown lower TP than control, they had all other HRV indexes similar to healthy dogs. So it is possible to infer that TP, which is an indicative of overall HRV, may be used to evaluate precocity alterations in autonomic control of the heart in dogs with DMVD. In a recent study, DMVD Cavalier King Charles Spaniel dogs without heart failure also had decreasing TP when compared to control (Rasmussen et al., 2012). Similar to Veterinary Medicine, it was demonstrated that men in early stages of heart disease show decreasing TP values (Kleiger et al., 2005).

In the present research there was a difference in LF data when it was measured in $\mathrm{ms}^{2}$ or in normalized units (n.u.). Regarding the results in $\mathrm{ms}^{2}$, there was no difference between the groups. However, in n.u., LF was significantly higher in DMVD heart failure dogs than in control. Although both are representative of the same frequency component, the measurement in n.u. leads to a more precise analysis, since the fluctuations related to VLF are minimized with such normalization. Although such difference has not been previously reported in Veterinary Medicine, data from this research is in accordance with results observed in Medicine, where heart disease patients show high LF values in n.u., but not in $\mathrm{ms}^{2}$ (Carney et al., 2005; Kleiger et al., 2005).

In addition, it was demonstrated that human patients in more advanced stages of heart disease start showing a decrease in the LF component. Patients with either severe ventricular dysfunction after acute myocardial infarction or with advanced stages of heart failure have decreased LF with a subsequent decrease in $\mathrm{LF} / \mathrm{HF}$ ratio, probably due to a continuous increasing in sympathetic tonus which blocks periodical oscillations of atrial sinus node (Kleiger et al., 2005). This was not detected in the sample studied even in DMVD heart failure dogs, highlighting the importance of periodically 
monitoring diseased patients with Holter, since LF (and therefore LF/HF ratio) response to HRV alterations seems to have prognostic value.

In Veterinary Medicine, Häggström et al. (1996) reported decreasing HRV in DMVD Cavalier King Charles Spaniel dogs when compared to healthy animals of the same breed. Although informative and promising, such work assessed HRV based on the natural logarithm of normal RR intervals of the conventional ECG tracing, and it is worldwide recognized that HRV may be evaluated considering Holter-derived indexes (Task Force, 1996). Such data (Häggström et al., 1996) may be representative of the TP variable and the results found here are in accordance with those previously described. Oliveira et al. (2012), studying time domain HRV in DMVD dogs, reported alterations in variables related to the parasympathetic control of the heart, earlier than those related to sympathetic. They inferred that vagal tonus withdrawal could play a primary role in the development of heart failure in DMVD. In the present data, however, such hypothesis could not be confirmed since alterations related to both sympathetic and parasympathetic control were found. Maybe similar findings could also be found here if a higher number of animals had been studied, or if the evaluation had been performed in an earlier time point.

A limitation of this work was that the diseased animals were under routine medical therapy for heart disease, including angiotensin-converting enzyme (ACE) inhibitor, furosemide, spironolactone, and digitalis. These therapies may result in misleading data because they can decrease heart rate and improve HRV. Although there is little information for veterinary patients, the effects of medical therapy under HRV have been investigated in Medicine. It was demonstrated that the use of ACE inhibitors do not decrease vagal tonus measured by HRV variables, as reviewed by Paker (1985). On the other hand, it was reported that men with symptoms of heart failure who were treated with metoprolol (Taçoy et al., 2007), or losartan and spironolactone (Shehab et al., 2008) showed high HRV as a result of the drug's administration. In the present study, even under cardiac therapy, DMVD heart failure dogs showed significantly lower overall HRV indicated by TP value. Therefore, it is possible to infer that HRV could be even lower if no medication was administered and that the duration of therapy may not have been long enough to cause an increase in HRV. Moreover, dogs with symptoms of heart failure under cardiac therapy are representative of real cases that veterinarians will encounter in clinical practice.

\section{CONCLUSION}

The development of heart failure secondary to DMVD concurred with alterations in cardiac rhythm and in the autonomic modulation of the heart, which are assessed by the Holter examination.

\section{ACKNOWLEDGEMENTS}

To "Fundação de Amparo à Pesquisa do Estado de Minas Gerais (FAPEMIG) for financial support for this project and "Coordenação de Aperfeiçoamento de Pessoal de Nível Superior" (CAPES) for the scholarship awarded to M. S. Oliveira.

\section{REFERENCES}

AKSELROD, S.; GORDON, D.; UBEL, F.A. et al. Power spectrum analysis of heart rate fluctuation: A quantitative probe of beat-to-beat cardiovascular control. Science, v.213, p.220-222, 1981.

ATKINS, C.; BONAGURA, J.; ETTINGER, S. et al. Guidelines for the diagnosis and treatment of canine chronic valvular heart disease. J. Vet. Intern. Med., v.23, p.1142-1150, 2009.

BOON, J.A. The echocardiographic examination. In: BOON, J.A. (Ed). Manual of veterinary echocardiography. Iowa: BLACKWELL PUBLISHING, 2006. p.35-150.

CALVERT, C.A. Heart rate variability. Vet. Clin. North Am.- Small Anim. Pract., v.28, p.1409-1427, 1998.

CALVERT, C.A.; JACOBS, G.J.; SMITH, D.D.et al. Association between results of ambulatory electrocardiography and development of cardiomyopathy during long term follow-up of Doberman pinchers. J.A.V.M.A., v.216, p.34-39, 2000.

CARNEY, R.M.; BLUMENTHAL, J.A.; FREEDLAND, K.E. et al. Low heart rate variability and the effect of depression on post-myocardial infarction mortality. Arch. Intern.Med., v.165, p.14861491, 2005. 
CROSARA, S.; BORGARELLI, M.; PEREGO, M. et al. Holter monitoring in 36 dogs with myxomatous mitral valve disease. Aust. Vet. J., v.88, p.386-392, 2010 .

FERREIRA, D.F. Análises estatísticas por meio de Sisvar para Windows versão 4.0. In: REUNIÃO ANUAL DA SOCIEDADE INTERNACIONAL DE BIOMETRIA, 45., 2000, São Carlos. Anais... São Carlos: [s.n.] 2000. p.255-258. (Resumo).

HÄGGSTRÖM, J.; HAMLIN, R.L.; HANSSON, K. et al. Heart rate variability in relation to severity of mitral regurgitation in Cavalier King Charles spaniels. J. Small Anim. Pract., v.37, p.69-75, 1996.

HÄGGSTRÖM, J.; HÖGLUND, K.; BORGARELLI, M. An update on treatment and prognostic indicators in canine myxomatous mitral valve disease. J. Small Anim. Pract., v.50, p.25-33, 2009.

HANSSON, K.; HÄGGSTRÖM, J.; KVART, C. et al. Left atrial to aortic root indices using two-dimensional and M-mode echocardiography in cavalier king charles spaniels with and without left atrial enlargement. Vet. Radiol. Ultrasound., v.43, p.568$575,2002$.

KLEIGER, R.E.; MILLER, J.P.; BIGGER, J.T.Jr. et $a l$. Decreased heart rate variability and its association with increased normality after acute myocardial infarction. Am. J. Cardiol.,v.59, p.256-262, 1987.

KLEIGER, R.E.; STEIN, P.K.; BIGGER, J.T.Jr. et al. Heart rate variability: measurement and clinical utility. Ann. Non. Electrocardiol.,v.10, p.88-101, 2005.

MARTIN, M.W.; STAFFORD, M.J.; CELONA B. Canine dilated cardiomyopathy: a retrospective study of signalment, presentation and clinical findings in 369 cases. J. Small Anim. Pract., v.50, p.23-29, 2009.

OLIVEIRA, M.S.; MUZZI, R.A.L.; ARAÚJO, R.B. et al. Heart rate variability parameters of myxomatous mitral valve disease in dogs with and without heart failure obtained using 24-hour Holter electrocardiography. Vet. Rec., v.170, p.622, 2012.

OLSEN, L.H.; MOW, T.; KOCH, J. et al. Heart rate variability in young, clinically healthy Dachshunds: influence of sex, mitral valve prolapse status, sampling period and time of day. J. Vet. Cardiol., v.1, p.7-16, 1999.
PAKER, M. Sudden unexpected death in patients with congestive heart failure: a second frontier. Circulation, v.72, p.681-685, 1985.

RASMUSSEN C.E.;FALK, T.; ZOIS, N.E. et al. Heart rate, heart rate variability, and arrhythmias in dogs with myxomatous mitral valve disease. J. Vet. Intern. Med., v.26, p.76-84, 2012.

SHEHAB, A.; ELNOUR, A.A.; STRUTHERS, A.D. A randomized, controlled, double-blind, cross-over pilot study assessing the effects of spironolactone, losartan and their combination on heart rate variability and QT dispersion in patients with chronic heart failure. C.V.J.A., v.19, p.292-296, 2008.

STEIN, P.K.; BOSNER, M.S.; KLEIGER, R.E. et al. Heart rate variability: A measure of cardiac autonomic tone. Am. Heart J., v.127, p.1376-1381, 1994.

TAÇOY, G.; BALCIOGLU, A.S.; ARSLAN, U. et al. Effect of metoprolol on heart rate variability in symptomatic patients with mitral valve prolapsed. $A m$. J. Cardiol., v.99, p.1568-1570, 2007.

Task force of the european society of cardiology and the north american society of pacing and electrophisiology. Heart rate variability: standards of measurements, physiological interpretation and clinical use. Circulation, v.93, p.1043-1065, 1996.

TILLEY, L.P. Principles of electrocardiographic recording. In: TILLEY, L.P. (Ed). Essentials of canine and feline electrocardiography interpretation and treatment. Philadelphia: LEA \& FEBIGER, 1992. p.21-39.

VANDERLEI, L.C.M.; PASTRE, C.M.; HOSHI, R.A. et al. Basic notions of heart rate variability and its clinical applicability. Braz. J. Cardiovasc. Surg., v.24, p.205-217, 2009.

WESS, G.; SCHULZE, A.; GERAGHTY, N. et al. Ability of a 5-Minute electrocardiography (ECG) for Predicting Arrhythmias in Doberman Pinschers with Cardiomyopathy in Comparison with a 24-Hour ambulatory ECG. J. Vet. Intern. Med., v.24, p.367371,2010 